\title{
Effects of Tip Clearance on Stall Inception in a Multistage Compressor
}

\author{
Reid A. Berdanier* and Natalie R. Smith" \\ Purdue University, West Lafayette, Indiana 47907, USA \\ Anna M. Young ${ }^{\dagger}$ \\ Whittle Laboratory, University of Cambridge, Cambridge CB3 ODY, UK \\ Nicole L. Key \\ Purdue University, West Lafayette, Indiana 47907, USA
}

\begin{abstract}
Rotor tip clearance height and the associated tip leakage flow have a significant effect on the performance and stability of compressors. Existing studies considering tip clearance effects on stability have been primarily limited to low-speed compressors, and many of these evaluated single-stage machines, which may not adequately represent stall trends for enginescale compressors. Furthermore, test campaigns for engine-scale compressors cannot provide instrumentation accessibility required for detailed stage performance and stall investigations. Using results collected from a three-stage intermediate-speed axial compressor with appreciable density rise, this study addresses these needs. In this paper, three rotor tip clearances are tested, ranging from $1.5 \%$ to $4 \%$ span (1\% to $3 \%$ chord). Previous studies have primarily shown a transition from short-length-scale spikes to longlength-scale modes as the clearance is increased, whereas the present study shows the opposite: a transition from modes to spikes with increased tip clearance. As a result, these data emphasize that a definitive trend does not exist between the stall inception mechanism and increasing tip clearance. Instead, the clearance effects alter stage matching with speed and change the stall inception mechanism. These results also elicit future research by preliminarily suggesting that stall inception mechanisms may be predictable from steady performance measurements collected in the stalling stage.
\end{abstract}

\footnotetext{
* Postdoctoral Research Associate, School of Mechanical Engineering, 500 Allison Road, Member AIAA.

${ }^{\dagger}$ Centre for Doctoral Training (CDT) Fellow in Gas Turbine Aerodynamics, Whittle Laboratory, Madingley Road.

¥ Associate Professor of Mechanical Engineering, 500 Allison Road, Associate Fellow AIAA.
} 


\section{Nomenclature}

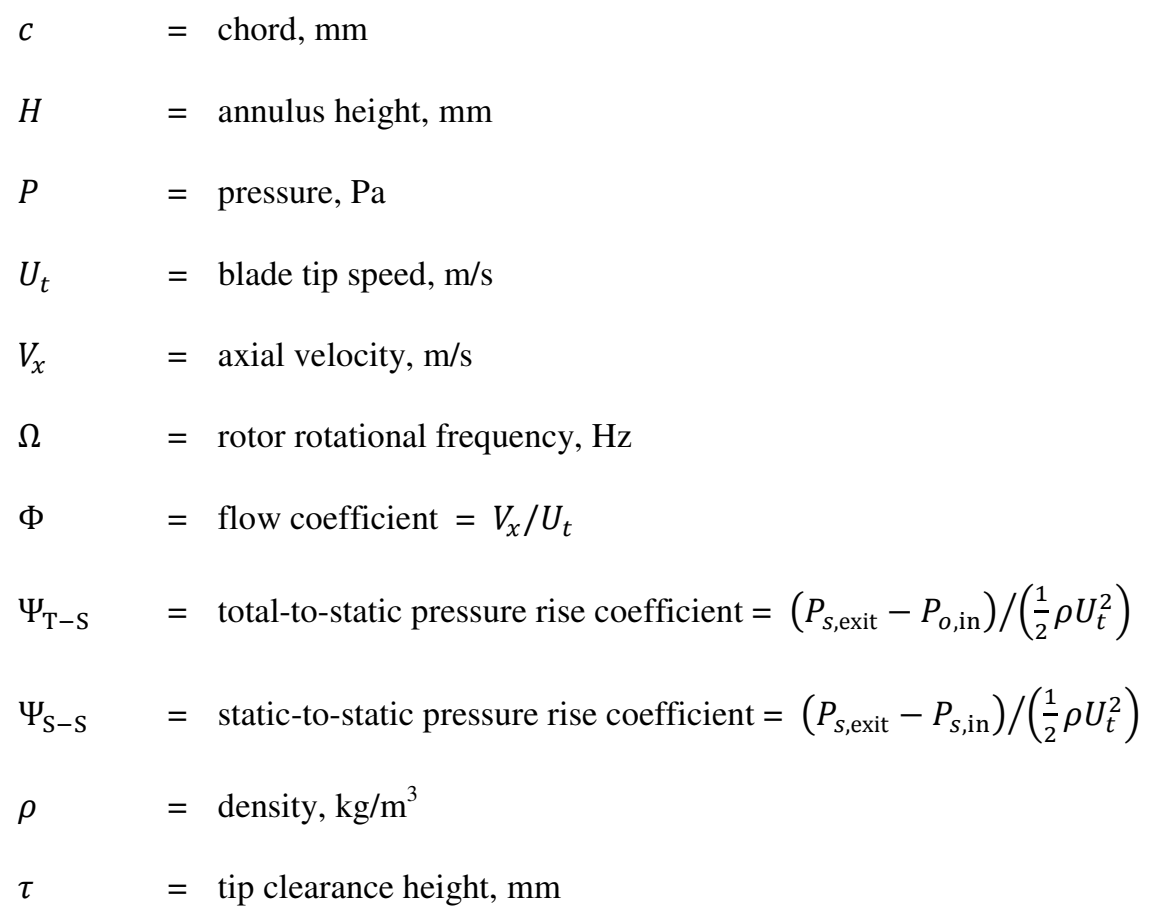

\section{Subscripts}

$A A \quad=$ area-average

in $\quad=$ compressor inlet condition

$o \quad=$ stagnation condition

$s \quad=\quad$ static condition

\section{Introduction}

THE onset of instabilities in compressors has been a focus of research for several decades. Emmons et al. [1] developed an early model for stall and surge, and Stenning [2] proposed that stall will occur at the peak of the totalto-static pressure rise characteristic. However, subsequent research beyond these early analyses showed that stall inception for axial compressors may come from two separate mechanisms.

McDougall et al. [3] first observed modal oscillations, or "modes," which are identified as long-length-scale disturbances representing a two-dimensional breakdown of flow within the entire machine. A brief review of modal stall-inception can be found by Paduano et al. [4]. Day [5] recorded a different process, in which short-length-scale "spike" disturbances develop as a result of localized flow breakdown, typically in one blade row. Studies focused on 
these spike-type stall mechanisms have recently been reviewed at length by Tan et al. [6]. Following Day [5], Camp and Day [7] showed that the model proposed by Stenning [2] is limited, and that the compressor will stall before the peak of the total-to-static characteristic if spike-type stall is initiated. From these and other analyses [8], it has been shown that the same compressor may exhibit different types of stall inception depending on conditions such as blade tip clearance, stagger angle, axial matching, and inlet distortion. Furthermore, Day et al. [9] showed that the stall inception mechanism of a multistage compressor can be altered by changing the rotational speed, which alters the stage matching. In three out of four compressors tested, the stall inception was shown to change from spike at low speed (emanating from the front stage) to modes at the design speed (when all stages are matched), before switching back to spike at high speed (initiated in the rear of the machine).

The effects of tip clearance size on axial compressor stability have been assessed in several research facilities and were often an associated component of the studies listed above. In particular, the results from McDougall et al. [3] and Day [5] have shaped general expectations of tip clearance effects on stall inception in axial compressors (whether single- or multistage, low- or high-speed). The connection between the tip leakage flow and stall inception has also been investigated explicitly by several authors, who have stated with growing confidence that forward-spillage of the tip leakage flow is the cause of spike-type stall inception [10-12]. Building upon the work of Inoue et al. [13], Weichert and Day [14] and Pullan et al. [15] determined that the spillage of the tip leakage flow forward of the rotor leading edge is not the driving force for spike-type stall initiation. Instead, these authors have found that a tornado-like vortex is shed from the rotor leading edge, and it is this vortex which propagates and grows into a stall cell. Although spike-type stall is not initiated directly by the tip leakage flow, the presence of the leakage flow may contribute to the leading edge separation which causes the formation of this vortex [15].

Recent studies [16-17] have sought to more clearly assess the effects of tip clearance on stall inception in axial compressors. However, the elusive nature of a definitive trend in the literature shows that the stalling tendencies of a particular compressor are difficult to predict, and so designers must resort to experiments [18]. Thus, additional research is warranted to encourage an understanding of stall inception mechanisms, which may ultimately allow for stall behavior prediction during the design process.

Day [19] provided a comprehensive review of past research and future outlook on stall research, with an added emphasis on the importance of stall studies in multistage machines with compressibility effects. Such data will benefit the community by bridging the gap between single-stage studies and real engine environments. Furthermore, 
Day incited a call to action to quantify stall behavior in machines with increased clearance-to-span ratios. As engine companies seek to fulfill small-core design goals, it is increasingly important to understand the influence of large tip gaps. In particular, decreasing blade heights in the rear stages of high pressure compressors lead to relatively large

tip gaps and contribute to performance and stability deficiencies. This study addresses these small core issues by providing information on the behavior of a three-stage intermediate-speed compressor with appreciable density rise and non-repeating stages. In this paper, the stall inception mechanisms are evaluated for three tip clearance sizes with normalized clearances up to $4.0 \%$ span (in excess of $2.5 \%$ chord).

\section{Experimental Methods}

The measurements for this study were collected from the three-stage axial compressor facility at Purdue University. The research compressor features an inlet guide vane (IGV) and three stages which model the rear stages of a high-pressure core compressor. The IGV and rotors are double circular arc designs, and the stators are NACA 65-series airfoils with two-dimensional radial profiles. At the design point, the flow exits the IGV at a mean flow angle of approximately 12 degrees, while the Stator 1 and Stator 2 exit mean flow angles are approximately 10 degrees, and the flow leaving Stator 3 is nominally axial [20]. The hub and casing diameters are constant, yielding a constant annulus area. Furthermore, the compressor operates at a corrected design speed of $5000 \mathrm{rpm}$, which is sufficient to yield an appreciable density rise (on the order of $8 \%$ per stage at the design point). Additional details of the compressor are given in Table 1.

Table 1. Purdue three-stage compressor design parameters.

\begin{tabular}{cc}
\hline \hline Parameter & Value \\
\hline Rotor Tip Diameter & $0.608 \mathrm{~m}(23.94 \mathrm{in})$. \\
Annulus Height (constant) & $50.8 \mathrm{~mm}(2 \mathrm{in})$. \\
Hub-to-tip Ratio & 0.833 \\
Rotational Speed (100\%) & $5000 \mathrm{rpm}$ \\
Nominal Tip Speed (100\%) & $159 \mathrm{~m} / \mathrm{s}(522 \mathrm{ft} / \mathrm{s})$ \\
Design Flow Coefficient & 0.53 \\
Design Pressure Rise Coefficient & 1.81 \\
Average Design Diffusion Factor & 0.45 \\
Average Design Stage Reaction & 0.69 \\
Rotor Blade Count (R1, R2, R3) & $36,33,30$ \\
Stator Vane Count (IGV, S1, S2, S3) & $44,44,44,50$ \\
\hline \hline
\end{tabular}


The stall inception measurements presented herein were collected in support of an extensive tip clearance sensitivity study aimed at understanding the effects of large rotor tip clearances on small core compressors. For this study, the tip clearance (TC) values tested were $1.5 \%, 3.0 \%$, and $4.0 \%$ span, and the configurations will be identified as TC-1.5, TC-3.0, and TC-4.0, respectively. Table 2 outlines these clearances relative to both blade span and chord. The tip clearance changes were accomplished through the use of casing recesses over the rotors, as described by Berdanier and Key [21], and shown graphically in Fig. 1. The casing recesses shown in Fig. 1 extend $40 \%$ axial chord upstream and downstream of the rotor blade (the recess is symmetric, although shown here only for the upstream section), and clearances were increased equally for all three rotors from one configuration to the next. Results summarizing the overall performance effects of rotor tip clearance on the compressor, including details regarding steady performance instrumentation and uncertainty, are available in Berdanier and Key [21]; only stall and stability effects will be considered here. The nominal tip clearances noted here are design-intent cold clearances; additional information about hot running clearances and variations across operating points can be found in Berdanier and Key [20,22].

Table 2. Tip clearance configurations and design intent clearance heights.

\begin{tabular}{cccc}
\hline \hline Configuration & $\begin{array}{c}\text { Nominal Clearance, } \\
\tau[\mathrm{mm}(\mathrm{in})]\end{array}$ & $\begin{array}{c}\text { Normalized Clearance, } \\
\tau / H[\%]\end{array}$ & $\begin{array}{c}\text { Normalized Clearance, } \\
\tau / c[\%]: \mathrm{R} 1, \mathrm{R} 2, \mathrm{R} 3\end{array}$ \\
\hline TC-1.5 & $0.762(0.03)$ & 1.5 & $1.07,1.01,0.96$ \\
TC-3.0 & $1.524(0.06)$ & 3.0 & $2.14,2.03,1.92$ \\
TC-4.0 & $2.032(0.08)$ & 4.0 & $2.85,2.70,2.56$ \\
\hline \hline
\end{tabular}

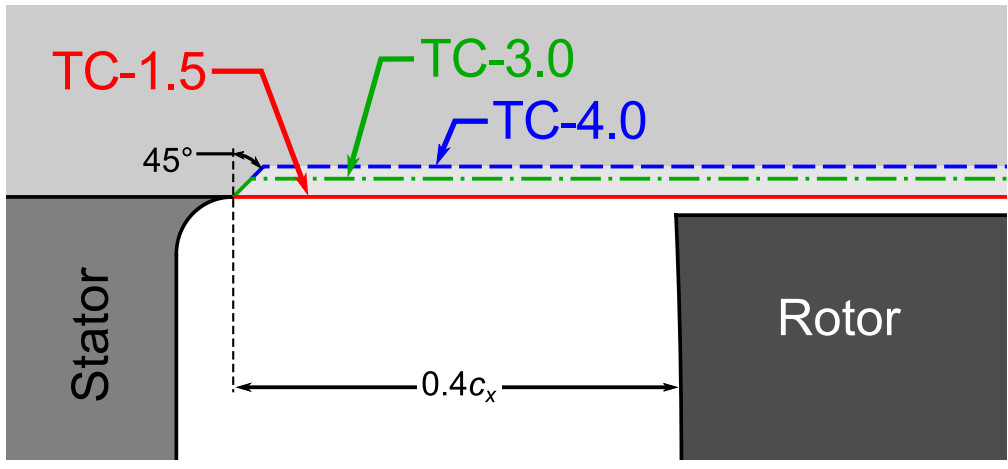

Figure 1. Schematic of compressor tip clearance casing geometry configurations (downstream part symmetric). 
For this study, the compressor stall behavior was assessed at several speeds for each clearance. In alignment with previous performance studies, corrected speeds of $100 \%, 90 \%, 80 \%$, and $68 \%$ were analyzed (68\% corrected speed was selected to avoid a Campbell diagram crossing that exists near $70 \%$ speed for a rotor first torsion (1T) vibratory mode). To account for circumferential variation of pressure across a stator pitch when measuring inter-stage pressures, the data presented in this paper correspond to pitchwise averages calculated by circumferentially indexing the stator vanes to several positions with respect to fixed pressure sensors.

The overall compressor map at four corrected speeds is presented in Fig. 2 along with stability lines identifying the onset of rotating stall at each operating speed. For each combination of speed and tip clearance, the stall point was determined by closing the throttle in incremental steps to increase the loading of the compressor. The mass flow rate at the onset of stall for each speed and tip clearance configuration was determined from an average of repeated tests.

To record the details of the stall inception process, a series of high-frequency response Kulite pressure transducers were installed throughout the compressor in several sensor arrangements, as outlined in Fig. 3. These sensors included standard B-type protective screens and were flush-mounted with the outer diameter of the flowpath. Following the design implemented by Houghton and Day [18], six sensors were positioned circumferentially around the compressor at an axial position of $15 \%$ axial chord upstream of each rotor (18 sensors in total, Kulite XTL-140-5G type). Additionally, an axial array of sensors was also installed at a particular circumferential location over each rotor and distributed axially $15 \%$ axial chord upstream of the rotor leading edge to $15 \%$ axial chord downstream of the rotor trailing edge. This axial array comprises $25 \mathrm{Kulite} \mathrm{XCS}-062-5 \mathrm{G}$ sensors, as shown graphically by a reduced number of sensors in Fig. 3.

For all sensor arrangements, data were sampled at a rate of $100 \mathrm{kHz}$ and low-pass filtered at $40 \mathrm{kHz}$. Immediately prior to installation and operation in the compressor, the sensors were calibrated over the full sensing range of 0 to 5 psig to achieve linear calibration coefficients. Uncertainties introduced by the measurement chain and the calibration process result in an overall measurement uncertainty of less than $0.2 \mathrm{kPa}(0.030 \mathrm{psig})$, or $0.6 \%$ of the full-scale range. 


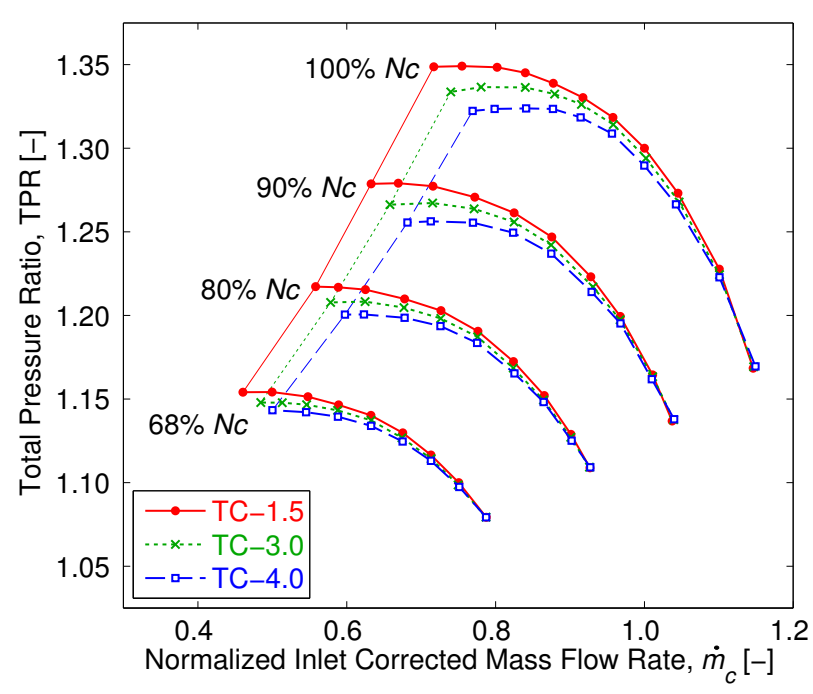

Figure 2. Compressor total pressure ratio map.

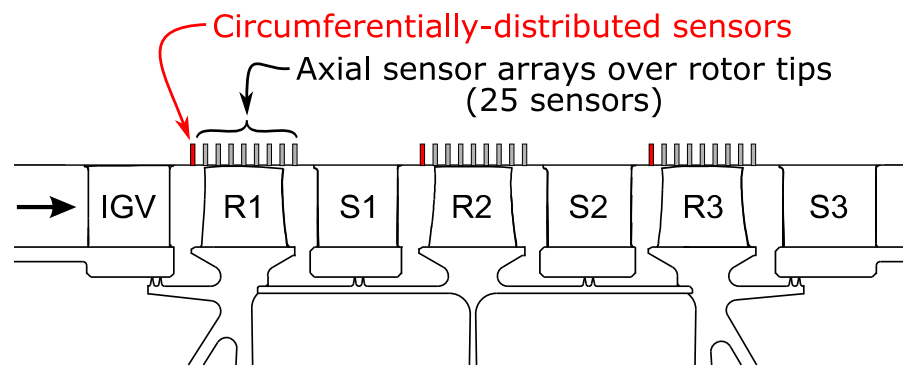

Figure 3. High-frequency response sensor arrangements.

\section{Results}

In this section, the effect of tip clearance on the stall inception behavior of the Purdue three-stage axial compressor will be presented for different operating speeds. In Part A, the stall inception characteristics for the baseline tip clearance, TC-1.5, are discussed in detail. Then, in Part B, stall inception differences associated with increased tip clearance (TC-3.0 and TC-4.0) will be considered.

Figure 4 encompasses many of the findings that will be discussed in both Parts A and B. This figure shows the static-to-static pressure rise characteristic, $\Psi_{\mathrm{S}-\mathrm{S}}$, across each stage of the compressor as a function of compressor inlet flow coefficient, $\Phi_{\text {in }}$, for the three different tip clearances. This figure enables the loading for an individual stage to be compared to the others. The uncertainty of measurements presented in Fig. 4 and all other pressure characteristics in this paper is within the symbol size on the charts. 
In Fig. 4, results for Stage 1 are shown in the top row, Stage 2 in the middle row, and Stage 3 in the bottom row. An important aspect of multistage compressor performance is stage matching, or how well the downstream stage can accommodate what is leaving the upstream stage. Since stage matching changes with rotational speed, the results are shown at four rotational speeds: $68 \% N_{c}$ in the first column, $80 \% N_{c}$ in the second, $90 \% N_{c}$ in the third, and $100 \%$ $N_{c}$ in the last column. Finally, the results from the three rotor tip clearances are also included in each graph. This figure is provided initially for future reference throughout this study. At this point, it is important to note that increasing the clearance has a detrimental effect on the work done by all three stages, especially at higher loading points.
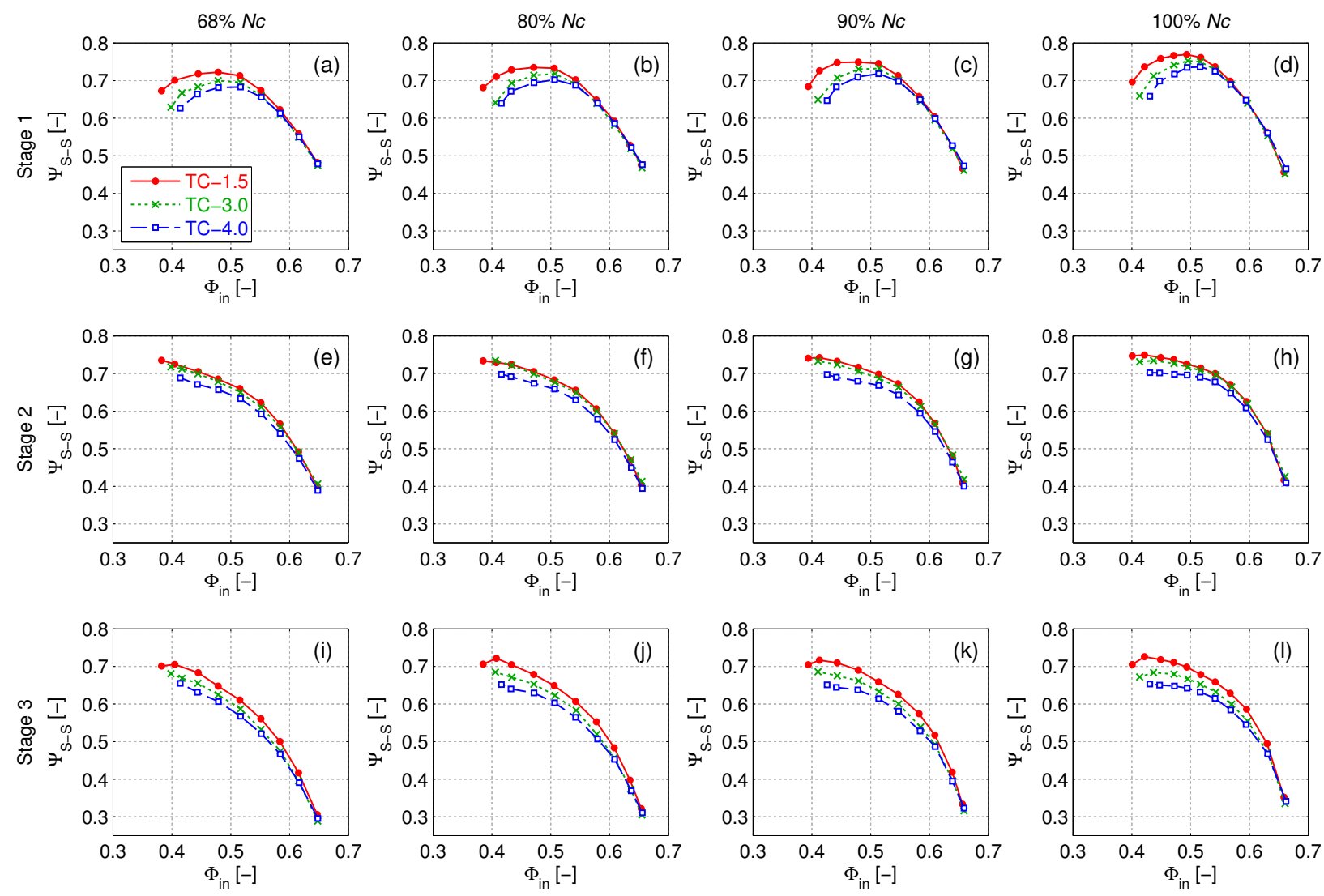

Figure 4. Stage static-to-static characteristics for all three tip clearances at four speeds versus compressor inlet flow coefficient: (a-d) Stage 1, (e-h) Stage 2, (i-l) Stage 3. 


\section{A. Baseline Clearance Results}

In this section, the characteristics for the compressor with baseline clearance will be discussed (solid lines with filled circles in Fig. 4). It can be seen in Fig. 4 that the static-to-static characteristic rolls over at low flows for all Stage 1 cases (top row). Furthermore, Stage 1 exhibits a characteristic with a positive slope over a significant portion of the flow range. The static-to-static characteristic for Stage 2 never rolls over, and the Stage 3 characteristic either levels out or rolls over slightly just before stall. This suggests that Stage 1 is consistently the weakest stage, and thus, the stalling stage for this machine with the baseline tip clearance.

Based on the observations of Camp and Day [7], the shape of the total-to-static pressure rise characteristics can be used to predict the stall inception mechanism of the compressor. Figure 5(a) shows the overall compressor totalto-static characteristics for each speed. (The stall point for each of the characteristics in Fig. 5 was calculated using calibrated high-frequency response pressure measurements covering the 50 rotor revolutions preceding stall.) The characteristic slopes are greater than or equal to zero for $100 \%$ and $90 \%$ corrected speed - a preliminary indication that long-length-scale modal oscillations will exist throughout the compressor prior to stall. However, the $80 \%$ and $68 \%$ corrected speed characteristics are still rising (negative slope) when the stall point is reached, and this indicates that spike-type stall will dominate. In addition, these data in Fig. 5(a) highlight the density rise through the machine as the characteristics for different operating speeds do not collapse onto one line.

In addition to the overall compressor total-to-static characteristics, it is also instructive to consider the total-tostatic characteristics for Stage 1, shown in Fig. 5(b). In this figure, the curves are vertically offset to allow differentiation of the results at different speeds. Comparing Fig. 5(a) and Fig. 5(b), it can be seen that the slopes of the Stage 1 characteristics at stall match those of the overall total-to-static characteristics at stall (Fig. 5 (a)). Both sets of characteristics are rising at stall for $68 \%$ and $80 \%$ speed, but rolled over for $90 \%$ and $100 \%$. Thus, an analysis of the Stage 1 characteristics (the stalling stage in this machine) predicts the same stalling mechanism (modes versus spikes) as the overall compressor analysis. In this case, once the stalling stage of the multistage compressor has been identified (Stage 1, based on Fig. 4 for the present compressor), the total-to-static characteristics of the stalling stage are sufficient to predict the stall inception mechanism of the whole compressor. 


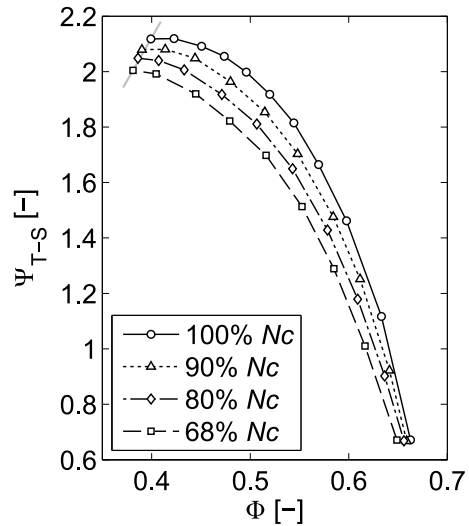

(a)

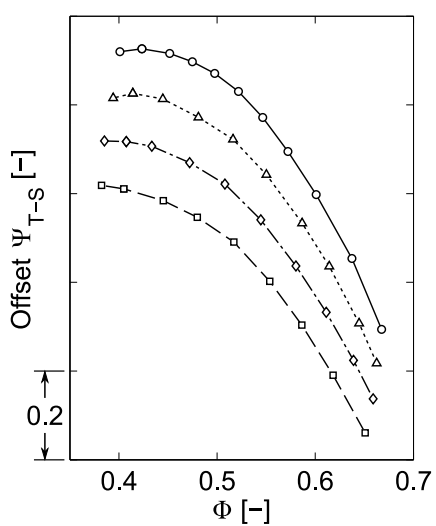

(b)

Figure 5. Total-to-static pressure rise characteristics for TC-1.5: (a) Overall, (b) Stage 1 with arbitrary offset.

High-frequency response pressure transducer signals acquired upstream of the rotor leading edges, shown in Fig. 6, confirm the stall inception predictions introduced above. In Fig. 6, static pressure measurements are presented from 15 revolutions prior to stall until 10 revolutions after stall. The results for each rotor are nominally offset on the ordinate to provide a visual tracking of the stall cells circumferentially around the compressor. Data collected at 100\% speed (Fig. 6(a)) show long-length-scale modes with a period of about three rotor revolutions, whereas $80 \%$ speed measurements (Fig. 6(b)) show spikes approximately three revolutions prior to stall with weak underlying modal disturbances preceding the onset of stall.

A separate study which simultaneously sampled hot-wire sensors inserted upstream of the rotors near the hub and tip, along with stall hysteresis studies, confirmed that the stall cells are full-span in nature at $100 \%$ speed. A single full-span stall cell is expected for all normal operating conditions with this compressor due to the low aspect ratio blading [19] and high hub-to-tip ratio design [22]. 


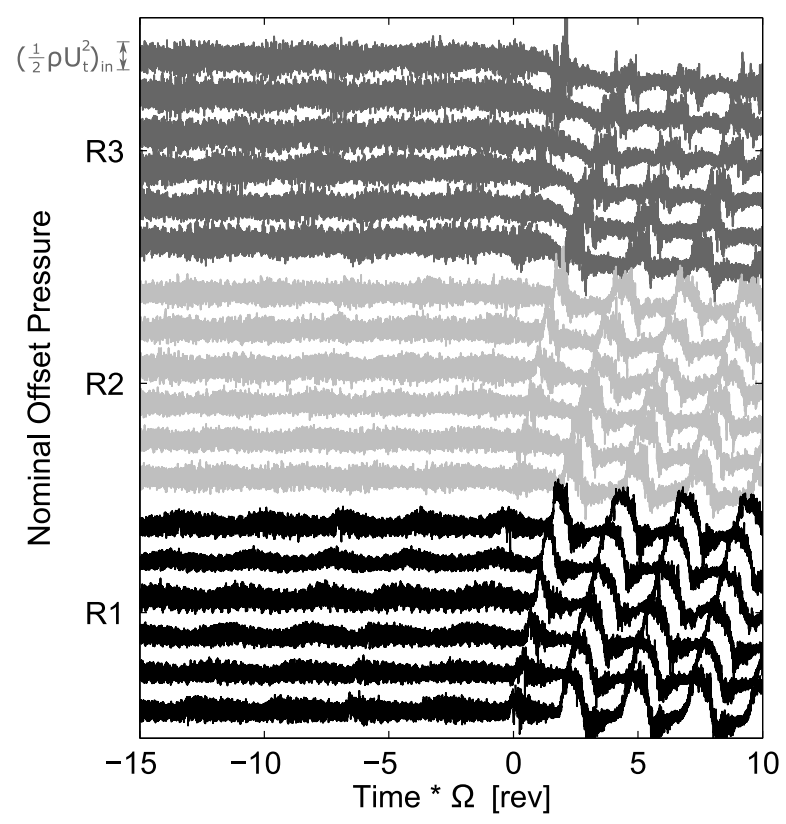

(a)

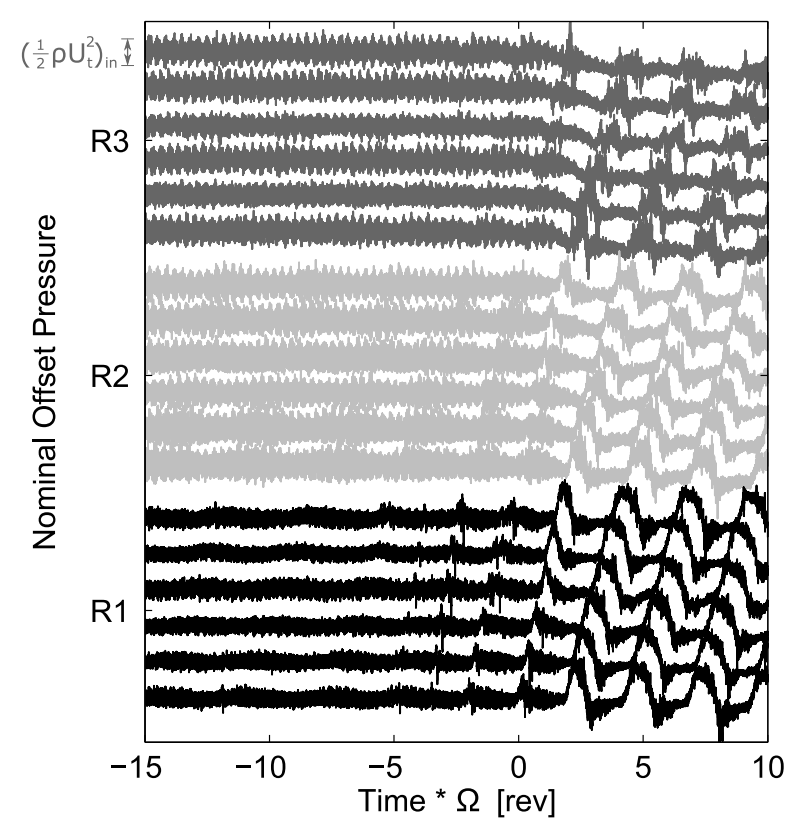

(b)

Figure 6. Raw static pressure traces entering stall for TC-1.5: (a) $100 \% N_{c}$ and (b) $80 \% N_{c}$.

The pressure signals in Fig. 6 are dominated by high-frequency content, making it difficult to identify pre-stall disturbances occurring at frequencies less than the rotor revolution frequency. Figure 7(a) shows similar data from 25 sensors positioned axially over Rotor 1 (see Fig. 3). A zoomed view of one revolution, Fig. 7(b) makes it possible to identify the 36 individual blade signals in one revolution for Rotor 1 . This view exposes that the high-frequency content identified in Fig. 6 represents coherent blade passing events superimposed upon the modal waves. To remove the blade passing events and highlight the underlying flow phenomena, a digital $5^{\text {th }}$ order Butterworth lowpass filter was implemented, following a procedure outlined by Cameron [24]. For the results presented in this study, a cutting frequency of $10 \Omega$ was selected. Several cutting frequencies were evaluated, and $10 \Omega$ was ultimately selected as an optimized balance of blade-passing event rejection without extensive smoothing of the low-frequency rotating stall events. The data presented in Fig. 7(c) correspond to the data in Fig. 7(a) after implementing the filter, and the resulting effect is a much more evident presence of modes in Fig. 7(c). 


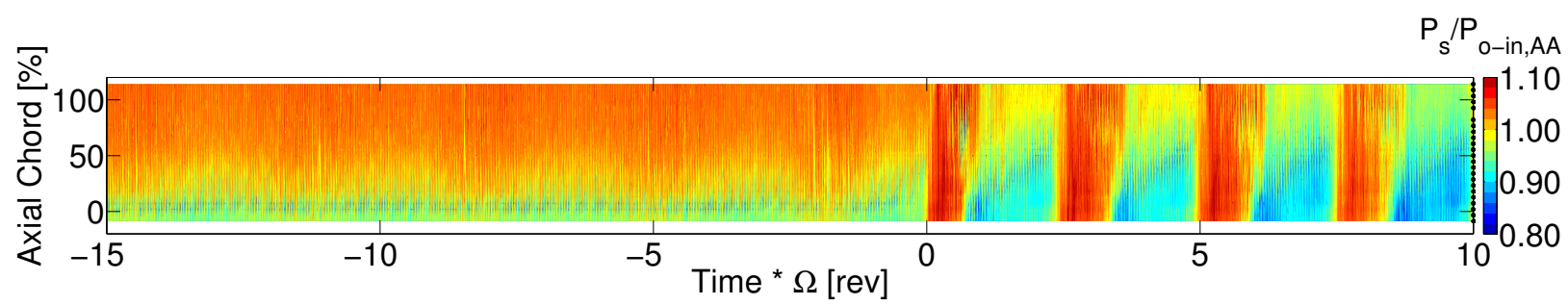

(a)

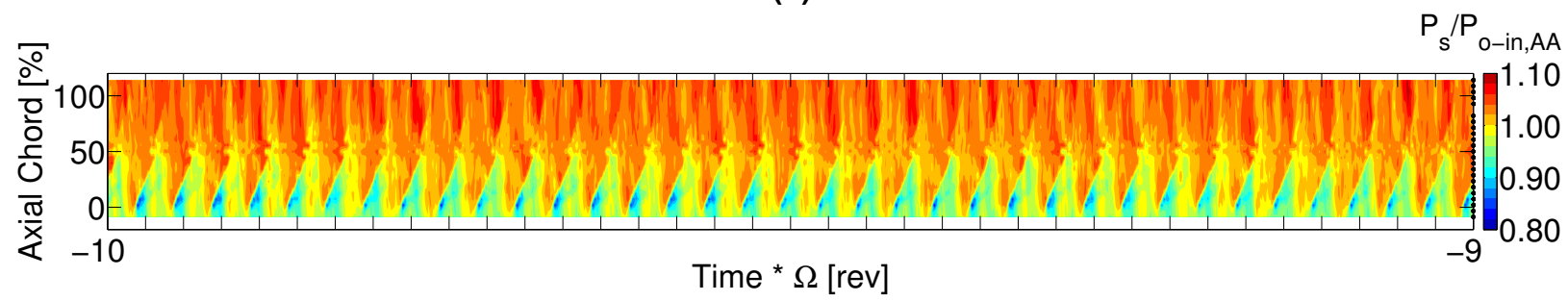

(b)

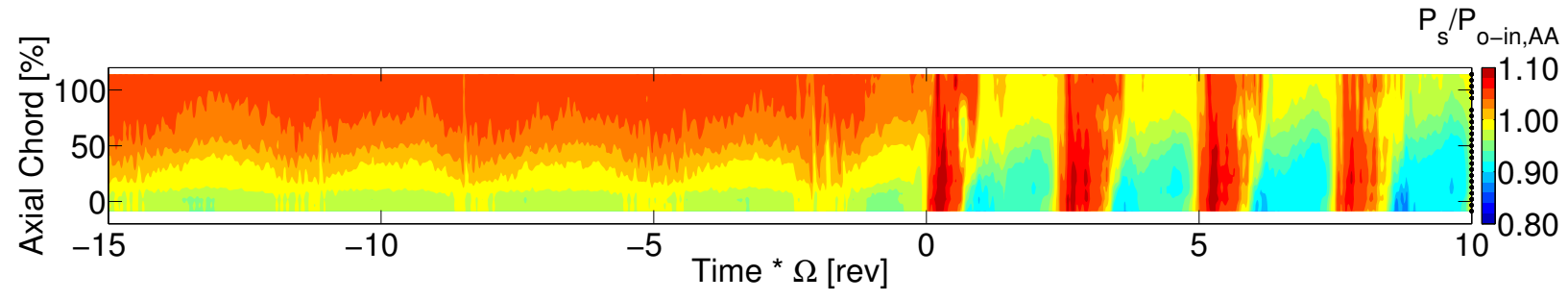

(c)

Figure 7. Pre-stall static pressure contours over Rotor 1 for TC-1.5 at $100 \% N_{c}$ : (a) Raw, (b) Raw data zoomed to highlight each blade passing signal in one revolution, and (c) Filtered data from $\operatorname{part}(\mathbf{a})\left(f_{c}=10 \Omega\right)$.

The same low-pass filter was also applied to the data from circumferentially-distributed sensors in Fig. 6 . The results (Fig. 8) show the same clear modes at $100 \%$ speed and very weak modes at $80 \%$ speed. In both cases, however, distinct spikes are also present at the peaks of the modal oscillations. For the $80 \%$ data in Fig. 8(b), the spikes are the ultimate stall inception mechanism, signified by the sequence of several spikes leading up to the stall event. This persistent multi-spike development at low-speed for TC-1.5 will be discussed further with the $68 \%$ speed data in subsequent discussion.

The spikes are always initiated in Rotor 1 and rotate at approximately $80 \%$ of rotor speed, while the modes rotate at approximately $30 \%$ of wheel speed. Closer inspection of Fig. 6 shows the spikes are present in the raw data, but they are difficult to discern because they are of the same order of magnitude as the blade passing disturbance. This shows that the filtering procedure introduced by Cameron is an important step in the procedure for processing stall inception data, in addition to analyzing the raw signals. In this case, it is likely that the sole use of unfiltered data 
would lead to the spikes being overlooked, and long-length-scale modal oscillations would likely be evaluated as the only initiators of stall.

The observation that spikes emerge in Rotor 1 supports the prediction above that Stage 1 is the sole initiator of stall even at high speed. When conditions support the development of modal waves, they appear in all stages as a system, thereby suggesting that the compressor is well-matched for such conditions and all three stages are reaching their stability limit at nearly the same time. However, Rotor 1 is still the "weakest" stage, as the local reduction in flow coefficient caused by the modes gives rise to spikes and drives Stage 1 into stall first (no such disturbances are generated by the presence of modes in Stage 2 or Stage 3).

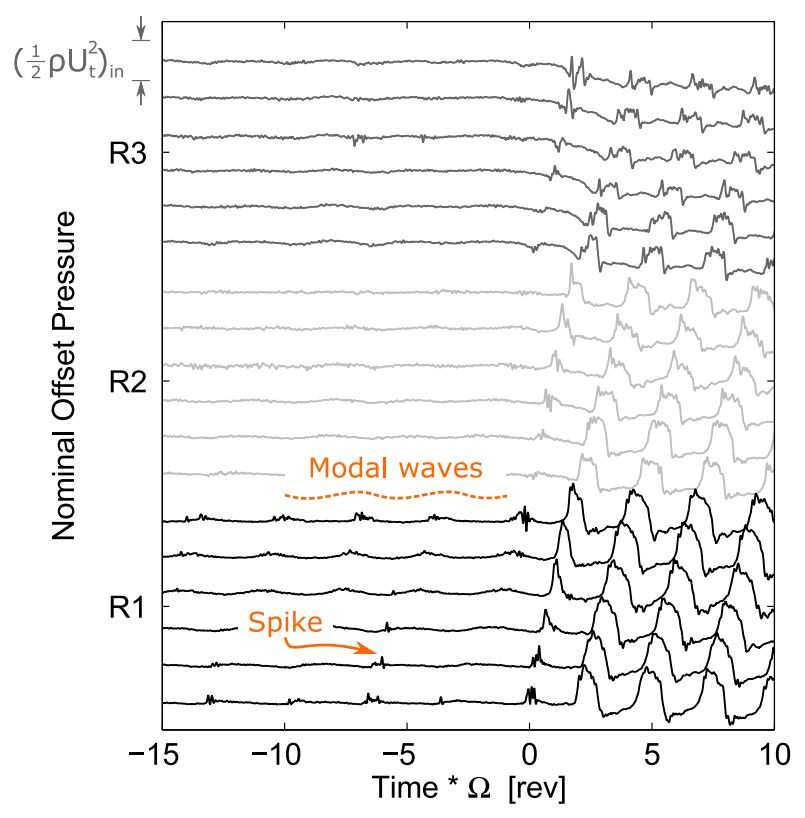

(a)

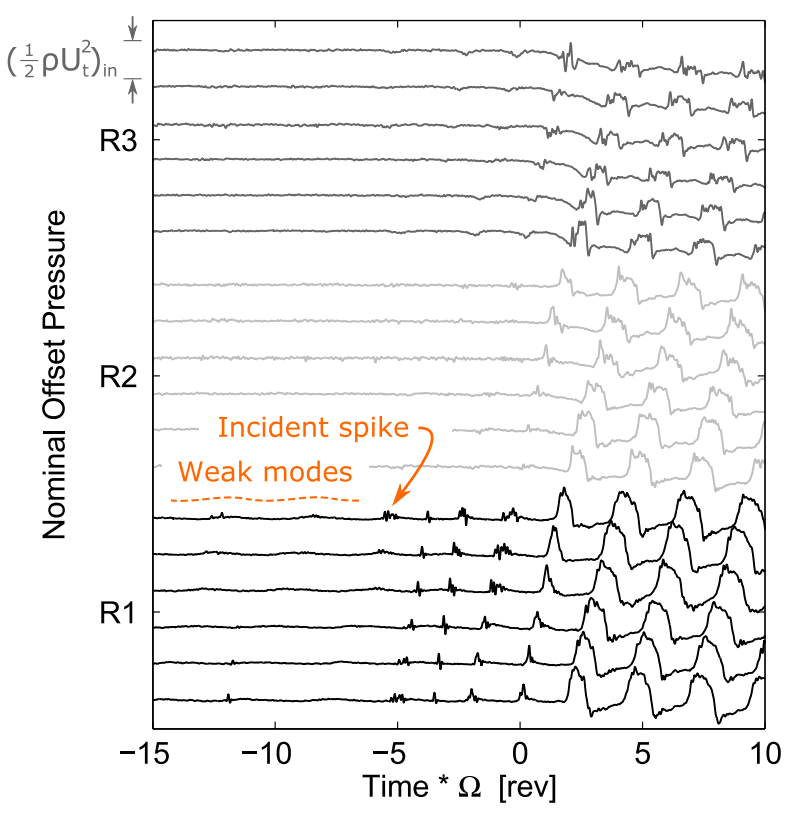

(b)

Figure 8. Filtered $\left(f_{c}=10 \Omega\right)$ static pressure traces entering stall for TC-1.5: (a) $100 \% N_{c}$, (b) $80 \% N_{c}$.

When this multistage compressor is operated at $68 \%$ speed and below, the stall behavior changes more substantially. These changes are due to changes in stage matching at part-speed operation, as explained by Cumpsty [25]. Specifically, the lower pressure rise produced by each stage causes the density entering the rear stages to be lower than expected. Mass conservation therefore requires the axial velocity to increase to compensate for the lower density, and thus, the flow coefficient into the rear stages is higher at lower rotor speeds. This higher flow coefficient at the rear of the machine dictates that the rear stages experience lower loading and are therefore 
further from stall, whereas Rotor 1 experiences higher loading and therefore less stable operation. Day et al. [9] also observed the opposite effect at speeds above design; the rear stages see higher density than expected, so the axial velocity and therefore flow coefficient are lowered towards the rear of the machine, causing stall to be initiated at the rear.

The matching effect is observed in the summarized results of Fig. 4. In this figure, the stability of Stage 1 is compromised early on the characteristic (the slope is positive for flow coefficients less than approximately 0.5) for all speeds. For the latter stages, however, the rollover observed at $100 \%$ speed diminishes as speed decreases, indicating increased stability in these stages with decreasing speed. By the time the speed is reduced to $68 \%$, the Stage 2 characteristics are continuing to rise when rotating stall overcomes the machine, and the rollover of the Stage 3 characteristic is much less extreme.

At low speeds, the increased stability of the rear stages allows the front stage to operate for an extended period of time in a stalled condition with a large number of stall cells. In some cases, bursts of spike activity are observed emanating from Rotor 1, but the stability of the rear stages allows Rotor 1 to recover to a stable operating condition. This is seen in Fig. 9, for $68 \% N_{c}$, for which an initial spike appears over Rotor 1 at approximately 30 revolutions prior to stall, and this single nascent stall cell persists until approximately 10 revolutions prior to stall. The presence of a spike stall cell in Rotor 1 is seen by Rotor 2 as a small blockage, i.e. a local reduction in flow coefficient. If Rotor 2 can accommodate this additional blockage, it will not pass on any disturbance to Rotor 3, as seen in Fig. 9, where there is no noticeable instability in Rotors 2 or 3 until less than 5 revolutions before the whole machine goes into stall. Ultimately, however, a chain of intense spikes occurs and Rotor 1 is unable to recover: at approximately 10 revolutions prior to stall, a new stall cell develops, resulting in approximately two spikes for every three revolutions at a fixed sensor location, as shown in Fig. 9. As the nascent stall cells rotate at slightly different speeds, one will eventually catch up with the other and they merge. This merging of the two cells creates an instability which is too great for the aft stages to support, and the entire compressor stalls.

The mis-matching of a compressor has been shown in previous work to generate substantial pre-stall disturbances. For example, Mailach et al. [26] found 'rotating instabilities' in the third stage of a four-stage machine when the clearance was enlarged over stage three alone (so stage three was operating past its natural stall point due to the stabilizing influence of the stages around it). In his discussion on the same paper, Cumpsty argues that these 'rotating instabilities' are in fact stall cells; an argument supported by the fact that Wisler et al. [23] did not observe 
any such disturbances when they carried out the same measurements on an identical compressor but with increased clearance over all four stages. Thus, the presence of stall cells in one stage which are prevented from spreading to the whole machine by the stabilizing influence of the stronger stages has been reported before. To the authors' knowledge, this is the first time that such a phenomenon has been generated via part-speed operation.

Based on observations at the four primary speeds identified in Fig. 2, additional stall measurements at $60 \%$ and $52 \% N_{c}$ were also collected. These data showed the same phenomena, but with longer periods of high-frequency pre-stall activity for lower rotational speeds. This capability of the rear stages to support a stalled Rotor 1 was discussed briefly by Foley [26], and a similar conclusion was reached by Longley and Hynes [28] in a multistage compressor matching assessment. However, the detailed measurements presented here extend previous authors' comments with simultaneous measurements from a highly-instrumented research compressor. Further analysis will also show the influence of increased tip clearance on this phenomenon.

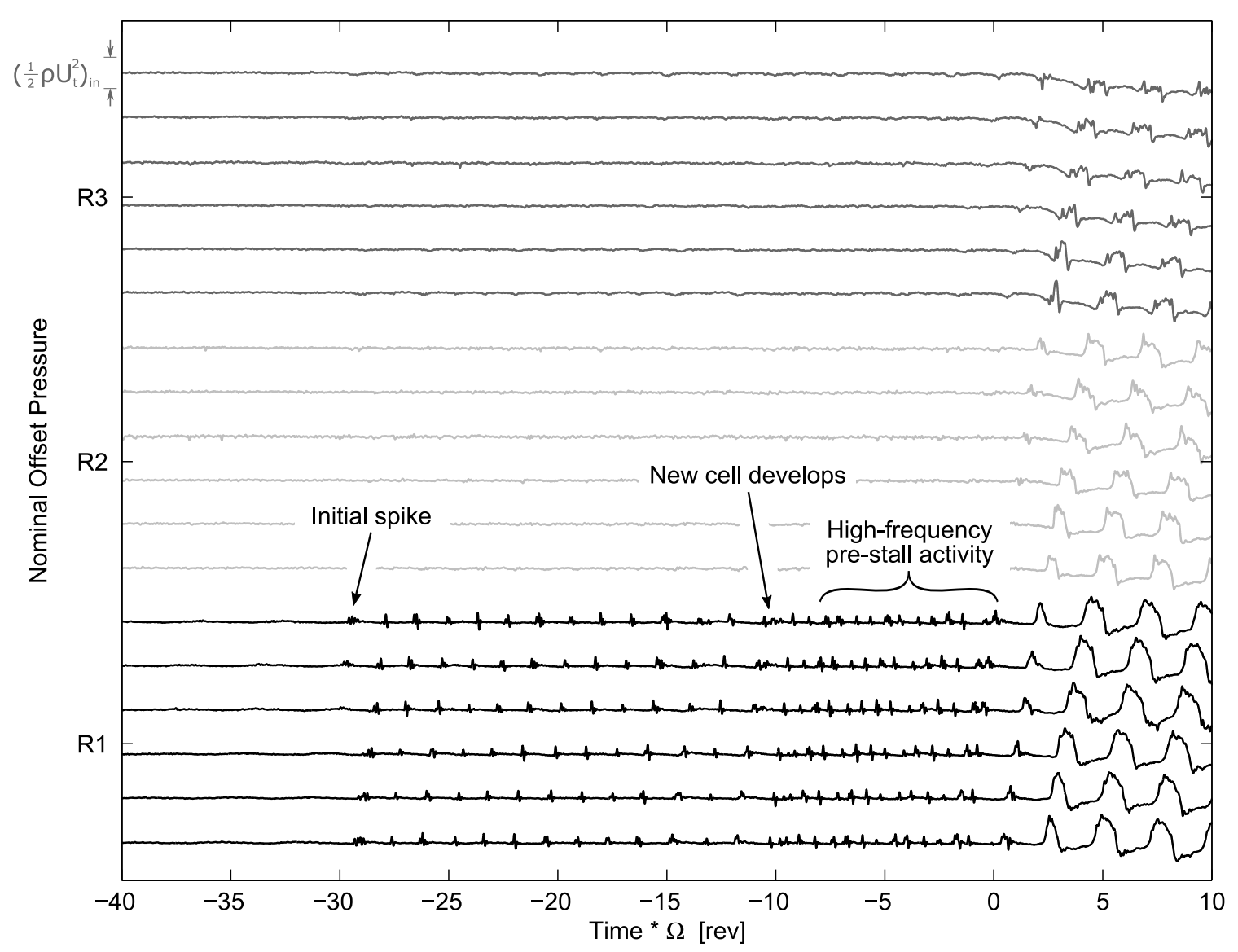

Figure 9. Filtered $\left(f_{c}=10 \Omega\right)$ static pressure traces entering stall for TC-1.5 at $68 \% N_{c}$. 


\section{B. Effect of Increased Tip Clearance}

The effects of increased tip clearance on the stall inception mechanisms of axial compressors were evaluated experimentally by Day [5] and Young [16]. These results were largely in agreement, showing that a compressor with small tip clearance will tend to exhibit spike-type stall, but that the mechanism changes to modal stall as the tip gap is increased (the change from spikes to modes occurred for normalized clearances of approximately 1.5 to $3.0 \%$ chord). This general trend was observed in low-speed single-stage compressors (Deverson [5] and Cambridge Yellow [16]), and also an intermediate-speed four-stage machine with repeating stages (C106 [5]). However, in the context of multistage tip clearance analyses, these C106 results have limitations. First, the repeating stage design inherently encourages all stages to stall simultaneously, therefore decreasing opportunities to consider stage matching. Also, the C106 measurements incorporated increased tip clearance over Rotor 1 only, dictating that stage 1 would be artificially weakened relative to the other stages.

Similar conclusions regarding stall and rotor tip clearance have been reached using computational simulations. Specifically, Vo [10] conducted computational analyses of stall inception mechanisms with different tip clearances using the $\mathrm{GE}^{3}$ rotor $\mathrm{B}$ configuration. In its four-stage low-speed repeating-stage test configuration, the GE $\mathrm{E}^{3}$ geometry exhibited spike-type stall emanating from Rotor 1 [30]. Vo's simulations of an isolated rotor showed spike-type stall with small tip clearance ( $1.2 \%$ chord) and modes with large tip clearance $(3.0 \%$ chord), agreeing with the experimental observations by Day [5] and Young [16].

These past research efforts $[5,10,17]$ initially suggest a generalizable delineation between increased rotor tip clearance and a transition from spike-type stall to modal stall inception. Despite these observations, however, it has been suggested that other characteristics (e.g., stage matching [29-30] and axial gap [31]) may have a greater influence on the stall inception mechanism than the tip clearance height. In fact, the remainder of this study will evaluate a hypothesis that a clear relationship between the clearance height and the stall inception mechanism does not exist.

As with the baseline configuration, TC-1.5, the total-to-static pressure rise characteristics of the whole machine can be analyzed first to predict the stall inception mechanisms using the criterion outlined by Camp and Day [7]. However, Stage 1 characteristics will also be considered for comparison following the discussion accompanying Fig. 5. Specifically, it is postulated that the total-to-static characteristics for the stalling stage are sufficient to predict 
the stalling behavior of the entire multistage machine. At this point the stalling stage is assumed to be Stage 1 based on the rollover of the static-to-static characteristics in Fig. 4. The prediction made on this basis will then be compared to the stall inception details recorded by the time-resolved static pressure traces.

The Stage 1 characteristics are compared for all three tip clearances in Fig. 10. Here, Fig. 10(a) contains a new comparison featuring the same data previously shown for TC-1.5 in Fig. 5(b). For TC-3.0, Fig. 10(b), only show a rollover at $100 \% N_{c}$, suggesting that modes will be present only at this speed with enlarged clearance. This differs from the smaller clearance configuration, TC-1.5 in Fig. 10(a), which also portrayed strong modes at 90\% (not shown explicitly in this paper) and weak modes at $80 \%$. In the filtered casing static pressure traces for TC-3.0 at 100\% speed, Fig. 11(a), modes are difficult to identify, but a closer look at the pre-stall behavior, Fig. 11(b), confirms the presence of modes, as predicted by the total-to-static characteristics for both the whole machine and Stage 1. For TC-3.0, pre-stall modal waves are still clearly identifiable, but the spike-type disturbances are more prevalent prior to the final stall inception than they were with the smaller clearance (compare Fig. 11(a) to Fig. 8(a)). Upon further increasing the rotor tip clearance to TC-4.0, Fig. 11(c), the pre-stall modal disturbances disappear entirely at $100 \%$ speed. As expected, in all cases the stall inception begins in Stage 1, which is the weakest stage (based on rollover of the static-to-static characteristics in Fig. 4). The stall inception results and characteristic slopes are summarized in Table 3. It can be seen that the slopes of the total-to-static characteristics of the whole machine and Stage 1 always agree with the observed stall inception mechanism.

Additional conclusions follow from this assessment of tip clearance effects. First, in Fig. 11(a-b), the rotational speed of the modes for TC-3.0 is nearly the same as TC-1.5 (approximately $30 \%$ of wheel speed). However, the rotational speed of the spikes shows a steady decrease with increased tip clearance, as outlined in Table 4. This decrease in speed is likely linked to the increase of spike "size" with clearance, as spikes will always rotate more slowly when they contain more fluid. Further, based on the observed development of modal waves noted here, the static-to-static characteristics in Fig. 4 are re-evaluated. In Fig. 4, it can be noted that the conditions which lead to the formation of modal oscillations show static-to-static characteristics with stall slopes greater than or equal to zero for all three stages, suggesting that all stages are unstable. This supports the original notion that modal waves indicate a well-matched multistage compressor. 


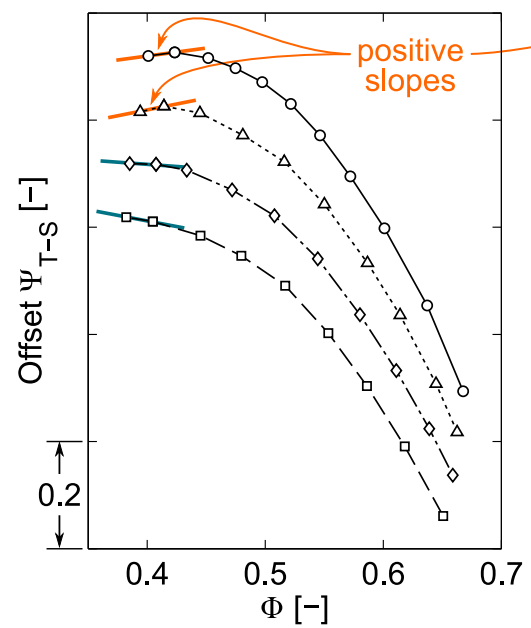

(a)

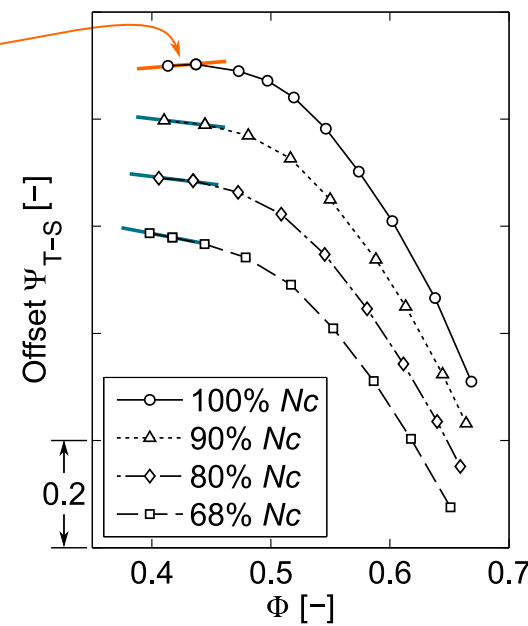

(b)

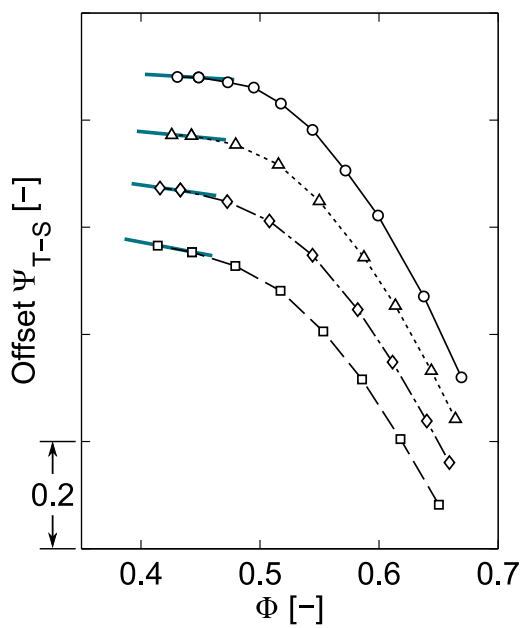

(c)

Figure 10. Stage 1 total-to-static pressure rise characteristics with arbitrary offset: (a) TC-1.5, (b) TC-3.0, and (c) TC-4.0. Characteristics with a positive slope at stall are identified.

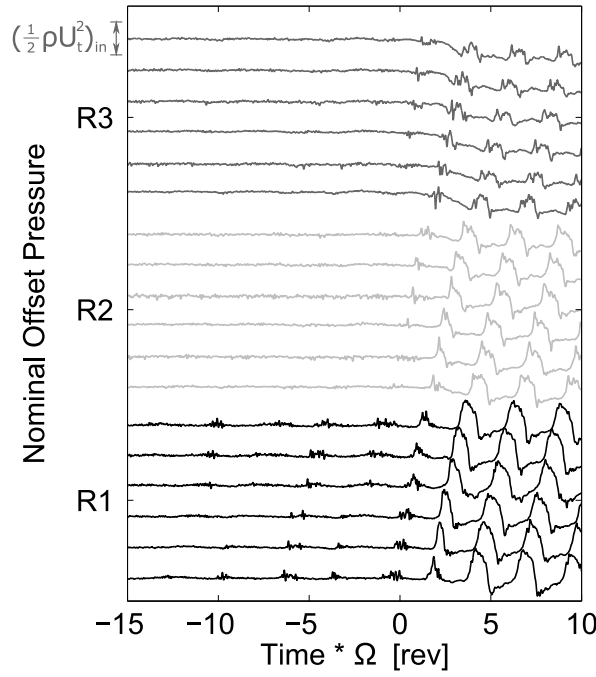

(a)

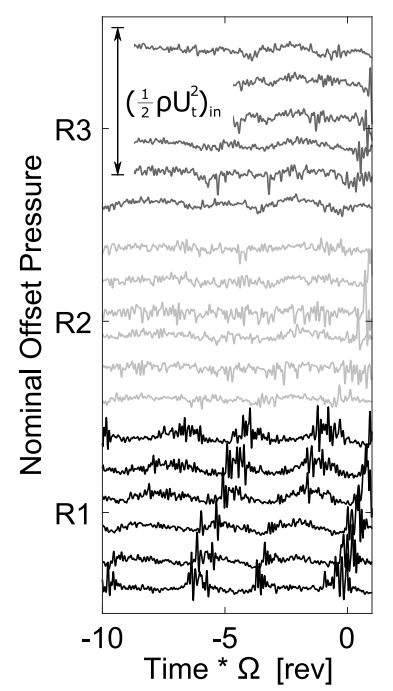

(b)

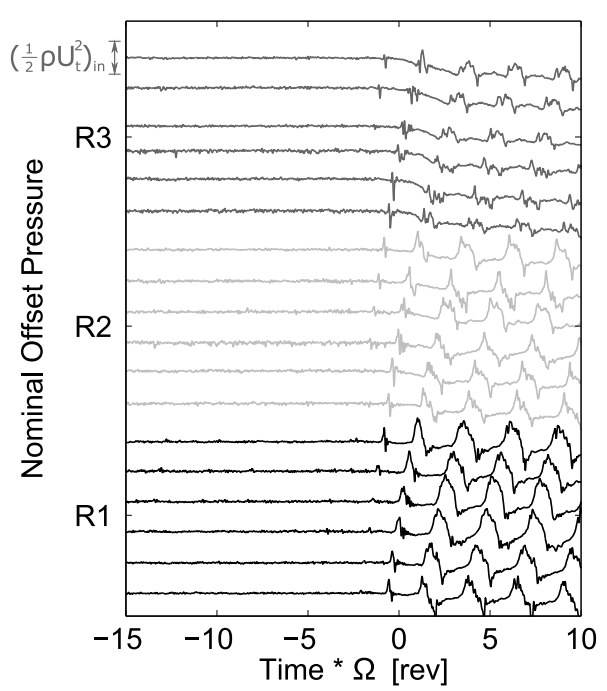

(c)

Figure 11. Filtered $\left(f_{c}=10 \Omega\right.$ ) static pressure traces entering stall at 100\%: (a) TC-3.0, (b) TC-3.0 (zoomed on pre-stall), and (c) TC-4.0.

Table 3. Summary of stall inception mechanisms and characteristic slopes for all configurations.

\begin{tabular}{ccccccccccccc}
\hline \hline TC Configuration & 1.5 & 1.5 & 1.5 & 1.5 & 3.0 & 3.0 & 3.0 & 3.0 & 4.0 & 4.0 & 4.0 & 4.0 \\
Speed $\left[\% N_{c}\right]$ & 100 & 90 & 80 & 68 & 100 & 90 & 80 & 68 & 100 & 90 & 80 & 68 \\
\hline Machine $\Psi_{\text {T-S }}$ Slope & + & + & - & - & + & - & - & - & - & - & - & - \\
Stage $1 \Psi_{\text {T-S }}$ Slope & + & + & - & - & + & - & - & - & - & - & - & - \\
Mechanism & $\mathrm{M}$ & $\mathrm{M}$ & $\mathrm{S}$ & $\mathrm{S}$ & $\mathrm{M}$ & $\mathrm{S}$ & $\mathrm{S}$ & $\mathrm{S}$ & $\mathrm{S}$ & $\mathrm{S}$ & $\mathrm{S}$ & $\mathrm{S}$ \\
\hline \hline
\end{tabular}


Table 4. Approximate rotational frequency of pre-stall phenomena at $100 \%$ speed.

\begin{tabular}{ccc}
\hline \hline Configuration & $\Omega_{\text {mode }} / \Omega[\%]$ & $\Omega_{\text {spike }} / \Omega[\%]$ \\
\hline TC- 1.5 & 30 & 85 \\
TC-3.0 & 30 & 80 \\
TC-4.0 & N/A & 70 \\
\hline \hline
\end{tabular}

The stage-by-stage static-to-static characteristics in Fig. 4 also provide information concerning the changes in stage loading with increased tip clearance (i.e., the relative offsets in the characteristics give a comparison of changes in the pressure rise capability of each stage). Of particular interest is the response to increased clearance of Stage 2 at different speeds. When the clearance is doubled from TC-1.5 to TC-3.0, there is almost no identifiable change in the static-to-static loading coefficient at $68 \%$ and $80 \%$ speed, and there is only a small change at $90 \%$ and $100 \%$ speed (approximately 5\% at the stall point). However, when the clearance is increased from TC-3.0 to TC-4.0, (from $3 \%$ to $4 \%$ span), there is a much more noticeable change in the static-to-static loading coefficient at all speeds.

The behavior of Stage 1 is nearly opposite to that of Stage 2 in that it shows a much more drastic loss in pressure rise when the clearance is increased from TC-1.5 to TC-3.0, but far less of a drop in response to the change from TC-3.0 to TC-4.0. Thus, from TC-1.5 to TC-3.0, the first stage does less work, but Stage 2 achieves almost the same pressure rise at TC-3.0 as it did for the baseline tip clearance.

When the tip clearance is increased to TC-4.0, the pre-stall activity identified over Rotor 1 at part-speed (Fig. 9) is much less pronounced, as shown in Fig. 12, which shows results for $68 \% N_{c}$ with TC-4.0. In this figure, it can be seen that there are no pre-stall instabilities in Rotor 1; a typical spike-type stall development occurs instead with propagation through all three stages following an initial strong spike. This behavior shown in Fig. 12 is markedly different from that observed for TC-1.5 in Fig. 9, where stall cells are observed to emanate frequently from Rotor 1 while Rotor 2 and Rotor 3 continue to operate stably. This suggests that the increase in clearance has caused a change in matching: with a small clearance, Rotor 2 and Rotor 3 are able to suppress stall cells from Rotor 1 because they have sufficient stall margin that they can operate stably with small amounts of additional blockage at inlet. It takes a larger blockage to destabilize the whole machine (in Fig. 9, this appears to come from two stall cells forming close to each other). When the clearance is enlarged, however, the first spike to form in Rotor 1 leads directly to stall, suggesting that Rotor 2 and Rotor 3 no longer have as much additional stall margin when Rotor 1 reaches its stability limit, and thus they can no longer accommodate any additional blockage due to a stall cell in Rotor 1 . The reasons for this change in matching are not clear from the data available, but the observed phenomenon shows that 
designers must consider changes in matching when estimating changes in stalling margin and behavior due to increased clearance. It can also be noted that the trend of decreasing spike rotation speed with clearance is also present at part-speed operation, such that the spikes in Fig. 12 propagate at $65 \%$ wheel speed (compared to $75 \%$ wheel speed for TC-1.5).

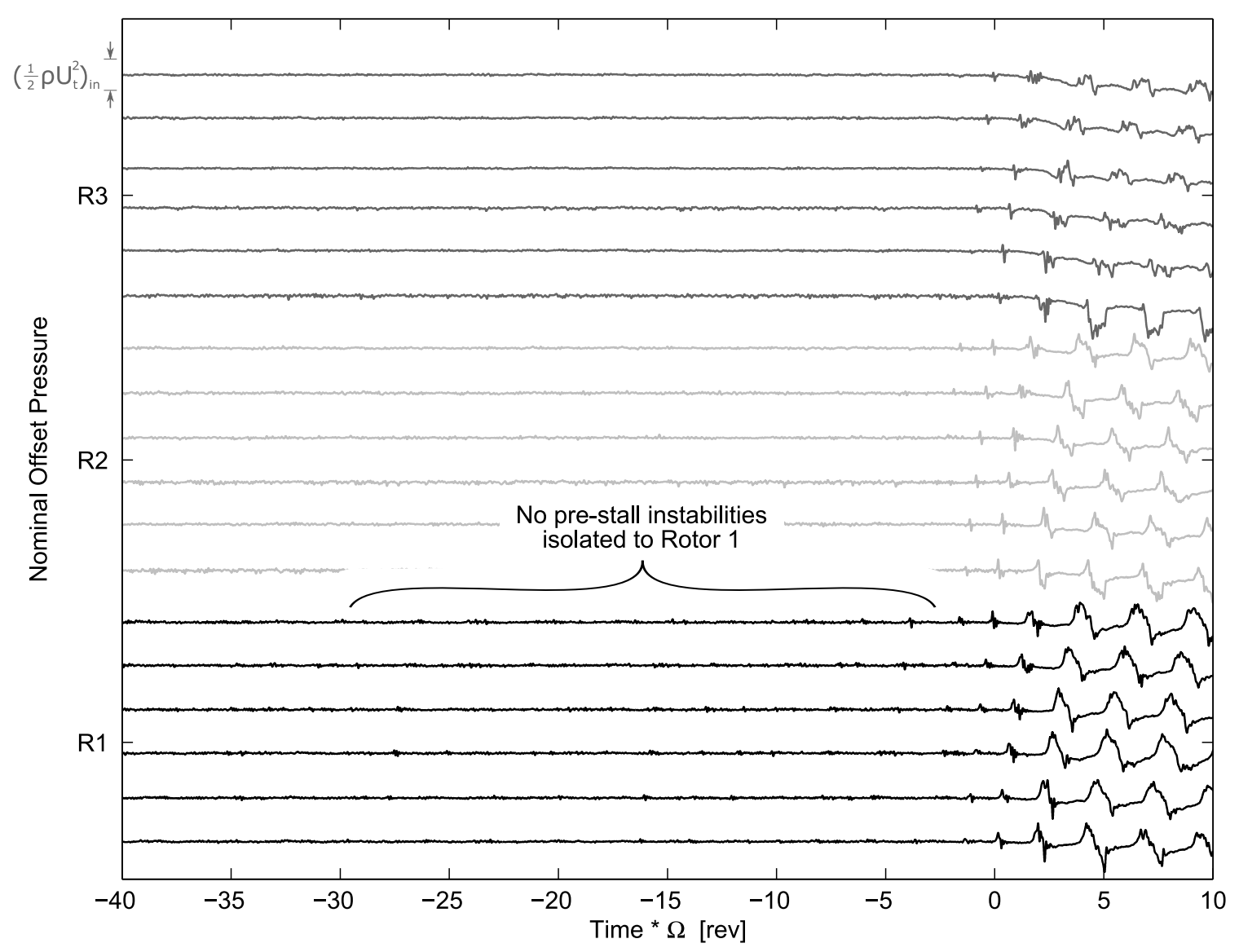

Figure 12. Filtered $\left(f_{c}=10 \Omega\right)$ static pressure traces entering stall for TC-4.0 at $68 \% N_{c}$.

The stall inception trends for the Purdue three-stage axial compressor were interrogated across six rotational speeds with each of the three rotor tip clearances. The observed behavior may be split into four main classifications which are mapped across the speeds and tip clearances, as shown in Fig. 13. Region 1 includes the design speed and baseline tip clearance, TC-1.5, where strong modal behavior exists with weak spike-type disturbances providing the final route to stall. This region blends into Region 2 where the modal disturbances remain, but with decreased intensity and spike-type behavior dominates. Region 3 describes a series of conditions for which spike-type stall is the only stall inception mechanism present. This third region encompasses the majority of conditions studied, 
particularly with larger clearances. Finally, Region 4 denotes conditions for which Rotor 1 portrays spike-type disturbances occurring at a high frequency for a significant period of time during pre-stall operation. Region 4 occurs at rotor speeds less than or equal to 68\% speed primarily only for the design-intent tip clearance (TC-1.5), with similar observations at TC-3.0 appearing for some (but not all) tests. It can therefore be said that the change from modes to spikes observed with decreasing speed for the design clearance level (TC-1.5) fades away as the clearance increases. This finding suggests that the influence of clearance alters the shift of matching with speed, and thus changes the stall inception mechanism.

Ultimately, these results show that changes in stall inception behavior of a compressor with clearance are not only due to the direct effects of the tip clearance flow on the actual stalling process, but also due to the indirect effects of clearance on matching and, thus the overall stability of the machine. Therefore, whereas single-stage studies are valuable for determining the details of the tip clearance flow and the stall inception process, the underlying behavior of a full engine compressor can only be studied effectively in a multistage environment. This information tells designers of compressors with enlarged clearance (or of compressors where a larger range of clearances is expected during operation) that they need to exercise caution when assuming that the mis-matching effect will tend to move the stall from the front to the rear of the machine as the speed is increased.

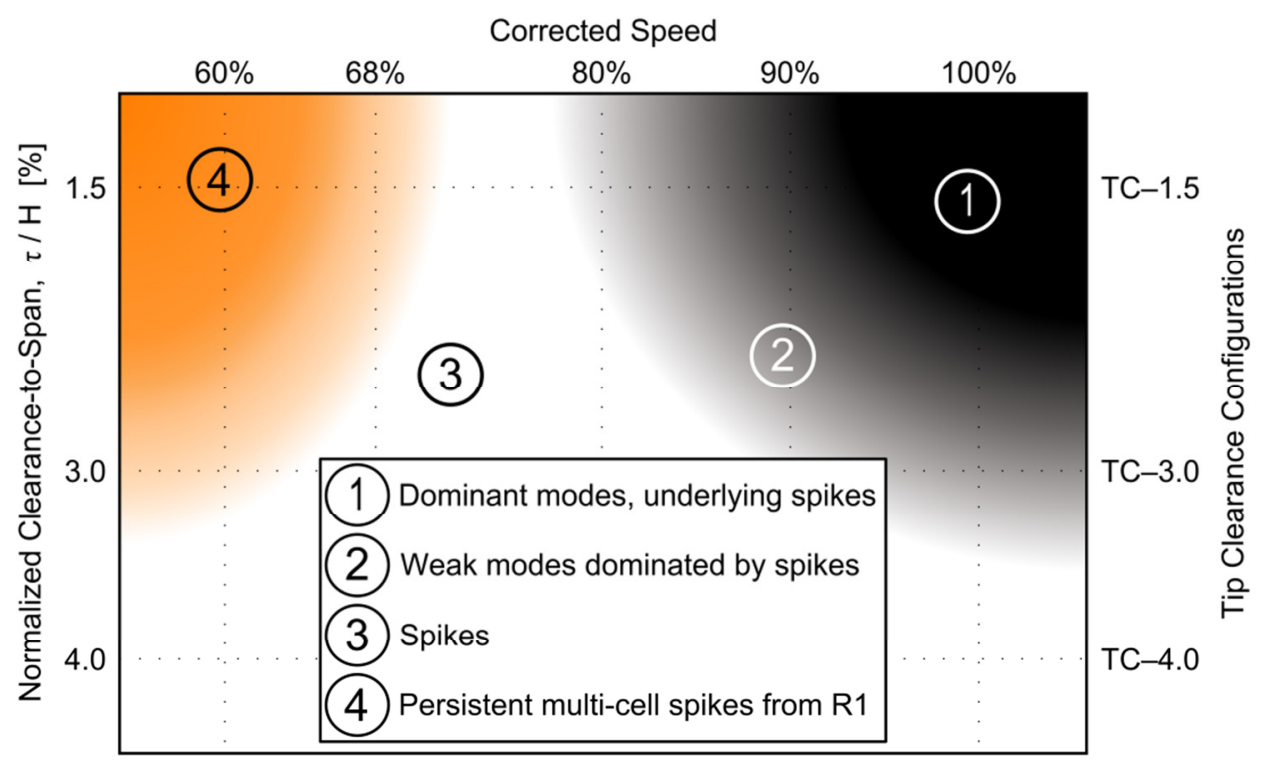

Figure 13. Summary of stall inception trends for all tested conditions. 


\section{Conclusions}

In this study, stall inception trends were evaluated in the Purdue three-stage axial compressor for three tip clearances within an operating envelope from $52 \%$ to $100 \%$ corrected speed. Using total-to-static pressure rise characteristics, the stall inception mechanisms were predicted for each speed based on the slope of the characteristic at the stall point. For the present compressor, Stage 1 is always the limiting stage, as shown by the consistent rollover in the Stage 1 static-to-static characteristics and supported by time-resolved static pressure measurements during stall inception. For the compressor studied here, the total-to-static characteristics of the limiting stage are sufficient for predicting the slope of the characteristic for the whole machine at the stall point and, accordingly, correlate with the stall inception mechanism of the entire multistage machine. Further research is warranted to determine whether this observation is indicative of stall behavior for other multistage compressors.

The predictions of stall inception mechanism based on total-to-static characteristics were upheld by pre-stall traces of static pressure measured using high-frequency response piezoresistive Kulite pressure transducers. However, these data showed the importance of implementing digital low-pass filtering techniques to reveal underlying features which may be on the order of magnitude of the blade passing signal. Although filtering pressure signals to analyze stall inception mechanisms is a useful technique, it is still important to consider the raw pressure signal to ensure artificial disturbances (and therefore inaccurate conclusions) are not introduced by the filtering process.

For this compressor, the design intent tip clearance geometry at $100 \% N_{c}$ has strong pre-stall modal behavior with weak spike-type behavior. It is difficult to identify the spikes, which develop at the peaks ${ }^{\S}$ of the modal waves and cause the final flow breakdown, without removing the blade passing disturbances. As the rotational speed is decreased, the long-length-scale modal disturbances disappear and the compressor exhibits clear spike-type stall inception. This is due to the change in stage matching at low speed, which causes Stage 1 to become less stable, and Stages 2 and 3 to be moved away from their stall points, thus encouraging the development of localized spike-type stall cells in Stage 1. These stall cells eventually extend to Stages 2 and 3 and cause the whole machine to go into stall.

To assess the effects of increased tip clearance in this multistage environment, two increased tip clearance heights (TC-3.0 and TC-4.0) were tested in the same manner as the baseline tip clearance configuration (TC-1.5).

\footnotetext{
$\S$ As presented here, the spikes develop at the peaks of the modes defined by pressure data. However, the spikes appear at the troughs of the modes when considering velocity data (e.g., hot-wire measurements).
} 
Specifically, this three-stage compressor showed a change from modal to spike-type stall inception characteristics as the rotor tip clearance was increased. This is in contrast to previous experience in the open literature which utilized both single-stage and multistage compressors and showed a trend from spike to modal stall inception with increasing clearance. As a result, the present study shows an explicit relationship between the clearance height and the stall inception mechanism is unlikely to exist. Instead, the effect of tip-clearance on stage matching influences the stall inception mechanism of the machine indirectly.

\section{Acknowledgments}

The authors would like to thank Ivor Day, John Longley, John Adamczyk, and Nick Cumpsty for their helpful insights while interpreting results. This material is based upon work supported by NASA under the ROA-2010 NRA of the Subsonic Fixed Wing project, with Technical Monitor Mark Celestina, and in part by the National Science Foundation Graduate Research Fellowship Program under Grant No. DGE-1333468.

\section{References}

[1] Emmons, H.W., Pearson, C.E., and Grant, H.P., "Compressor surge and stall propagation," Transactions of the ASME, Vol. 79, 1955, pp. 455-469.

[2] Stenning, A.H., "Rotating Stall and Surge," Journal of Fluids Engineering, Vol. 102, No. 1, 1980, pp. 14-20. doi: $10.1115 / 1.3240618$

[3] McDougall, N.M., Cumpsty, N.A., and Hynes, T.P., "Stall Inception in Axial Compressors," Journal of Turbomachinery, Vol. 112, No. 1, 1990, pp. 116-123. doi: 10.1115/1.2927406

[4] Paduano, J.D., Greitzer, E.M., and Epstein, A.H., "Compression system stability and active control," Annual Review of Fluid Mechanics, Vol. 33, 2001, pp. 491-517. doi: 10.1146/annurev.fluid.33.1.491

[5] Day, I.J., "Stall Inception in Axial Flow Compressors," Journal of Turbomachinery, Vol. 115, No. 1, 1993, pp. 1-9. doi: $10.1115 / 1.2929209$

[6] Tan, C.S., Day, I., Morris, S., and Wadia, A., "Spike-Type Compressor Stall Inception, Detection, and Control,” Ann. Rev. Fluid Mechanics, Vol. 42, 2010, pp. 275-300. doi: 10.1146/annurev-fluid-121108-145603 
[7] Camp, T.R., and Day, I.J., "A Study of Spike and Modal Stall Inception in a Low-Speed Axial Compressor," Journal of Turbomachinery, Vol. 120, No. 3, 1998, pp. 393-401. doi: 10.1115/1.2841730

[8] Simpson, A.K., and Longley, J.P., "An Experimental Study of the Inception of Rotating Stall in a Single-Stage Low-Speed Axial Compressor,” ASME Paper No. GT2007-27181, 2007.

[9] Day, I.J., Breuer, T., Escuret, J., Cherrett, M., and Wilson, A., "Stall Inception and the Prospects for Active Control in Four High-Speed Compressors," Journal of Turbomachinery, Vol. 121, No. 1, 1999, pp. 18-27. doi: $10.1115 / 1.2841229$

[10] Vo, H.D., "Role of Tip Clearance Flow on Axial Compressor Stability," Massachusetts Institute of Technology, Cambridge, MA, PhD Dissertation, 2001.

[11] Hoying, D.A., Tan, C.S., Vo, H.D., and Greitzer, E.M., "Role of Blade Passage Flow Structures in Axial Compressor Rotating Stall Inception,” Journal of Turbomachinery, Vol. 121, No. 4, 1999, pp. 735-742. doi: $10.1115 / 1.2836727$

[12] Bennington, M.A., Ross, M.H., Cameron, J.D., Morris, S.C., Du, J., Lin, F., and Chen, J., “An Experimental and Computational Investigation of Tip Clearance Flow and Its Impact on Stall Inception,” ASME Paper No. GT2010-23516, 2010. doi: 10.1115/GT2010-23516

[13] Inoue, M., Kuroumaru, M., Tanino, T., Yoshida, S., and Furukawa, M., "Comparative Studies on Short and Long Length-Scale Stall Cell Propagation in an Axial Compressor Rotor," Journal of Turbomachinery, Vol. 123, No. 1, 2001, pp. 24-30. doi: 10.1115/1.1326085

[14] Weichert, S., and Day, I., "Detailed Measurements of Spike Formation in an Axial Compressor," Journal of Turbomachinery, Vol. 136, No. 5, 2014, 051006 (9 pages). doi: 10.1115/1.4025166

[15] Pullan, G., Young, A.M., Day, I.J., Greitzer, E.M., and Spakovszky, Z.S., "Origins and Structure of SpikeType Rotating Stall," Journal of Turbomachinery, Vol. 137, No. 5, 2015, 051007 (11 pages). doi: $10.1115 / 1.4028494$

[16] Young, A., Day, I., Pullan, G., "Stall Warning by Blade Pressure Signature Analysis," Journal of Turbomachinery, Vol. 135, No. 1, 2013, 011033 (10 pages). doi: 10.1115/1.4006426

[17] Young, A.M., "Tip Clearance Effects in Axial Compressors," University of Cambridge, Cambridge, UK, PhD Dissertation, 2012. 
[18] Houghton, T., and Day, I., "Stability Enhancement by Casing Grooves: The Importance of Stall Inception Mechanism and Solidity," Journal of Turbomachinery, Vol. 134, No. 2, 2012, 021003 (8 pages). doi: $10.1115 / 1.4002986$

[19] Day, I.J., "Stall, Surge, and 75 Years of Research," Journal of Turbomachinery, Vol. 138, No. 1, 2016, 011001 (16 pages). doi: 10.1115/1.4031473

[20] Berdanier, R.A. and Key, N.L., "An Experimental Investigation of the Flow Physics Associated with End Wall Losses and Large Rotor Tip Clearances as Found in the Rear Stages of a High Pressure Compressor," NASA/CR-2015-218868, 2015.

[21] Berdanier, R.A., and Key, N.L., "The Effects of Tip Leakage Flow on the Performance on Multistage Compressors Used in Small Core Engine Applications," Journal of Engineering for Gas Turbines and Power, Vol. 138, No. 5, 2016, 052605 (10 pages). doi: 10.1115/1.4031625

[22] Berdanier, R.A. and Key, N.L., "Experimental Investigation of Factors Influencing Operating Rotor Tip Clearance in Multistage Compressors," International Journal of Rotating Machinery, Vol. 2015, 2015, 146272 (13 pages). doi: 10.1155/2015/146272

[23] Wisler, D.C., Beacher, B.F., and Shin, H.-W., "Effects of loading and clearance variation on tip vortex and endwall blockage," Proceedings of $9^{\text {th }}$ International Symposium in Transport Phenomena and the Dynamics of Rotating Machinery (ISROMAC), Honolulu, HI, February 10-14, 2002.

[24] Cameron, J.D., "Stall Inception in a High-Speed Axial Compressor," University of Notre Dame, Notre Dame, IN, PhD Dissertation, 2007.

[25] Cumpsty, N.A., "Discussion: 'Comparative Studies on Short and Long Length-Scale Stall Cell Propagation in an Axial Compressor Rotor' (Inoue, M., Kuroumaru, M., Tanino, T., Yoshida, S., and Furukawa, M., Journal of Turbomachinery, Vol. 123, No. 1, 2001, pp. 24-30)," Journal of Turbomachinery, Vol. 123, No. 1, 2001, pp. 31. doi: $10.1115 / 1.1326084$

[26] Mailach, R., Lehmann, I., and Vogeler, K., "Rotating instabilities in an axial compressor originating from the fluctuating blade tip vortex," Journal of Turbomachinery, Vol. 123, No. 3, 2001, pp. 453-460. doi: $10.1115 / 1.1370160$

[27] Foley, J.R., "Compressor Surge Topic at SAE Round Table," SAE Journal, Vol. 59, September, 1951, pp. 4650. 
[28] Longley, J.P., and Hynes, T.P., "Stability of Flow Through Multistage Axial Compressors," ASME Paper No. 89-GT-311, 1989. doi: 10.1115/89-GT-311

[29] Giannissis, G.L., McKenzie, A.B., and Elder, R.L., "Experimental Investigation of Rotating Stall in a Mismatched Three-Stage Axial Flow Compressor," Journal of Turbomachinery, Vol. 111, No. 4, 1989, pp. 418-425. doi: 10.1115/1.3262289

[30] Silkowski, P.D., "Measurements of Rotor Stalling in a Matched and Mismatched Multistage Compressor," MIT GTL Report No. 221, 1995.

[31] Inoue, M., Kuroumaru, M., Yoshida, S., and Furukawa, M., "Short and Long Length-Scale Disturbances Leading to Rotating Stall in an Axial Compressor Stage With Different Stator/Rotor Gaps," Journal of Turbomachinery, Vol. 124, No. 3, 2002, pp. 376-384. doi: 10.1115/1.1458022 